\title{
Drugs, including alcohol, that act as risk factors for cataract, and possible protection against cataract by aspirin-like analgesics and cyclopenthiazide
}

\author{
JOHN J HARDING AND RUTH VAN HEYNINGEN \\ From the Nuffield Laboratory of Ophthalmology, University of Oxford, Walton Street, Oxford OX2 6AW
}

SUMmARY A case-control study of cataract in Oxfordshire explored the risks and benefits associated with a variety of drugs. Steroids including the diuretic spironolactone, nifedipine, heavy smoking, and beer drinking were associated with a raised risk. On the other hand aspirin-like analgesics (paracetamol, ibuprofen, aspirin, etc.) appeared to protect against cataract. Cyclopenthiazide appeared to provide a similar protection.

Cataract is the major cause of blindness worldwide, but only recently have some major risk factors in cataract been elucidated in different countries..$^{1-5} \mathrm{We}$ conducted a case-control study of cataract in Oxford and have reported on the risks associated with diabetes, myopia, severe diarrhoea, glaucoma, and employment on a military base.$^{35}$ Here we report on drugs that appear to be risk factors for cataract in Oxford, and on drugs that appear to have protected against cataract.

\section{Material and methods}

Three hundred cases and 609 controls aged 50-79 were interviewed for this study. Cases were those patients aged between 50 and 79 having cataract extracted in the Oxford Eye Hospital. Cases and controls had the same age-sex distribution. ${ }^{5}$ Details of the recruitment, questionnaire, and data analysis have been reported. ${ }^{5}$ The subjects were asked what drugs they had taken regularly for at least four months at any time in the past. They were also asked about their current and past smoking and drinking habits. In the analysis of the data odds ratios were computed from contingency tables and are reported as valid estimates of relative risk. Thus a reported relative risk of 2 for a particular factor implies that the group exposed to that factor are twice as likely to be admitted for cataract extraction as those not exposed to that factor. Conversely a relative risk of 0.5 implies that the group exposed to the factor are protected against cataract, being only half as likely to have a cataract extracted as the unexposed group.

\section{Results}

\section{STEROIDS}

Long-term steroid therapy causes posterior subcapsular cataract, ${ }^{6}$ but in the present study consumption for as little as four months was scored. Nevertheless steroids emerged as a significant risk (Table 1). The steroids most commonly reported were prednisolone and spironolactone with a risk

Table 1 Steroids as a risk factor for cataract

\begin{tabular}{lccc}
\hline & Controls & Cases & Total \\
\hline Steroid & 38 & 32 & 70 \\
No steroid & 571 & 268 & 839 \\
Total & 609 & 300 & 909 \\
Percentage positive & $6 \cdot 2$ & $10 \cdot 7$ & \\
\hline
\end{tabular}

$\chi^{2}$ test, $\mathrm{p}<0.025$; relative risk $=1.79 ; 95 \%$ confidence limits $=1.09$ to $2 \cdot 93$.

Table 2 Diuretics and cataract

\begin{tabular}{llcl}
\hline & Controls & Cases & Total \\
\hline Reporting diuretics & 155 & 57 & 212 \\
No diuretics & 454 & 243 & 697 \\
Total & 609 & 300 & 909 \\
Percentage positive & $25 \cdot 5$ & 19.0 & \\
\hline
\end{tabular}

$\chi^{2}$ test, $\mathrm{p}<0.031$; relative risk $=0.69 ; 95 \%$ confidence limits $=0.49$ to 0.97. 
Table 3 Diuretics as protective agents in older patients (aged 70-79)

\begin{tabular}{lccc}
\hline & Controls & Cases & Total \\
\hline Reporting diuretics & 99 & 27 & 126 \\
No diuretics & 183 & 110 & 293 \\
Total & 282 & 137 & 419 \\
Percentage positive & $35 \cdot 1$ & $19 \cdot 7$ & \\
\hline
\end{tabular}

$\chi^{2}$ test, $\mathrm{p}<0.001 ;$ relative risk $=0.45 ; 95 \%$ confidence limits $=0.28$ to $0 \cdot 74$.

Table 4 Percentage of cases and controls reporting different diuretics

\begin{tabular}{|c|c|c|c|c|}
\hline & \multicolumn{2}{|c|}{ Present study } & \multicolumn{2}{|c|}{ Edinburgh* } \\
\hline & Control & Cases & Control & Cases \\
\hline Amiloride & 3.9 & $3 \cdot 3$ & $2 \cdot 8$ & $3 \cdot 5$ \\
\hline Bumetanide & $1 \cdot 3$ & 3.0 & 0.9 & $1 \cdot 2$ \\
\hline Bendrofluazide & $3 \cdot 3$ & $1 \cdot 7$ & 4.9 & $6 \cdot 6$ \\
\hline Cyclopenthiazide & $10 \cdot 8$ & 3.7 & 3.7 & $2 \cdot 7$ \\
\hline Frusemide & 3.9 & 3.7 & $3 \cdot 1$ & $6 \cdot 5$ \\
\hline Hydrochlorthiazide & $4 \cdot 8$ & $4 \cdot 0$ & - & - \\
\hline Spironolactone & $1 \cdot 8$ & $4 \cdot 0$ & - & - \\
\hline Triamterene & $1 \cdot 2$ & 0.7 & - & - \\
\hline Other & 1.8 & $2 \cdot 7$ & - & - \\
\hline
\end{tabular}

*from Clayton et al. ${ }^{1}$

Table 5 Cyclopenthiazide as a protective factor for cataract-contingency table

\begin{tabular}{lccc}
\hline & Controls & Cases & Total \\
\hline +Cyclopenthiazide & 66 & 11 & 77 \\
- Cyclopenthiazide & 543 & 289 & 832 \\
Total & 609 & 300 & 909 \\
Percentage positive & $10 \cdot 8$ & $3 \cdot 7$ & \\
\hline
\end{tabular}

$\chi^{2}$ test, $\mathrm{p}<0.001 ;$ relative risk $=0.31 ; 95 \%$ confidence limits $=0 \cdot 16$ to $0 \cdot 60$.

attached to each. The risk associated with spironolactone is discussed under diuretics.

\section{DIURETICS}

Diuretics have been reported as a risk factor in the Edinburgh study, ${ }^{\prime}$ but this did not emerge from our results. In fact diuretics appeared to provide some protection (Table 2), especially in older patients (Table 3 ). The imbalance between cases and controls differed for different diuretics, with an excess of cases for bumetanide and spironolactone contrasting with an excess of controls reporting bendrofluazide and cyclopenthiazide (Table 4). The Edinburgh study found excess reports of every diuretic except cyclopenthiazide in cases, whereas we found several diuretics with an excess in controls (Table 4). The age-sex distributions of our cases and controls were almost identical, whereas the Edinburgh study had
Table 6 Spironolactone as a risk factor for cataract

\begin{tabular}{lccc}
\hline & Controls & Cases & Total \\
\hline Spironolactone & 11 & 12 & 23 \\
Without spironolactone & 598 & 288 & 886 \\
Total & 609 & 300 & 909 \\
Percentage positive & $1 \cdot 8$ & $4 \cdot 0$ & \\
\hline
\end{tabular}

$\chi^{2}$ test, $\mathrm{p}<0.05 ;$ relative risk $=2.3 ; 95 \%$ confidence limits $=1.002$ to $5 \cdot 28$.

an excess of older cataract patients, who would increase the score for all diuretics. We analysed the data for each diuretic by $\chi^{2}$ test: only two produced significant results. Cyclopenthiazide (Navidrex K) appeared to be protective, decreasing the risk of cataract by a factor of nearly 3 (Table 5). The proportion of subjects reporting cyclopenthiazide was greater in each of the four control groups than in the cases. The only diuretic found to be a significant risk factor was spironolactone, with a relative risk of 2.3 (Table 6 ). This drug is a steroid, and the associated risk of cataract seems to be similar to that for the other steroids (Table 1). When subjects reporting spironolactone (a risk factor) and/ or cyclopenthiazide (a protective factor) were removed from the data, patients reporting other diuretics were equally distributed between the cases $(12.0 \%)$ and controls $(13.0 \%)$, so that the apparent protective effect of diuretics (Table 2) was entirely due to cyclopenthiazide.

\section{NIFEDIPINE}

Nifedipine has not been mentioned as a possible risk factor for cataract but it appeared to be so in our study (Table 7). The cases reporting nifedipine had no striking common feature except as expected for angina ( 5 out of 9 ) and hypertension ( 8 out of 9 ). This risk may be related to hypertension, which others have reported as a risk factor. ${ }^{1}$

\section{CIGARETTES}

Subjects were asked about their past and present use of cigarettes and number of years as a smoker. Daily cigarette consumption multiplied by years as a smoker gave a cigarette-year value which was used to group subjects. The highest group was more common among cases, and so a contingency table was drawn up comparing these 'heavy smokers' - that is, those whose cigarette-year score exceeded 1500-with non-smokers (Table 8 ). Only $2 \cdot 8 \%$ of the controls reported this level of smoking compared with $7 \%$ of cases. By our definition 'heavy smoking' of cigarettes was associated with a doubling of the risk of cataract. A similar increase was reported from Edinburgh.' 
Table 7 Nifedipine as a risk factor for cataract

\begin{tabular}{lccc}
\hline & Controls & Cases & Total \\
\hline Nifedipine & 7 & 9 & 16 \\
Without nifedipine & 602 & 291 & 893 \\
Total & 609 & 300 & 909 \\
Percentage positive & 1.2 & 3.0 & \\
\hline
\end{tabular}

$\chi^{2}$ test, $p<0.05 ;$ relative risk $=2 \cdot 7 ; 95 \%$ confidence limits $=1.00$ to $7 \cdot 32$.

Table 8 Cigarette smoking and cataract

\begin{tabular}{lccr}
\hline & Controls & Cases & Total \\
\hline 'Heavy smoker'* & 25 & 21 & 46 \\
Non-smoker & 241 & 103 & 344 \\
Total & 266 & 124 & 390 \\
Percentage positive $\dagger$ & $2 \cdot 8$ & $7 \cdot 0$ & \\
\hline
\end{tabular}

$\chi^{2}$ test, $\mathrm{p}=0.032$; relative risk $=1.97 ; 95 \%$ confidence limits $=1.05$ to 3.67.

*'Heavy smoker' means subjects with cigarette-year score $>1500-$ e.g. subject who smoked more than 30 cigarettes/day for 50 years or 40 cigarettes/day for 37.5 years, etc.

†Percentage of the total in the study.

Table 9 Beer drinking and cataract

\begin{tabular}{lccr}
\hline & Controls & Cases & Total \\
\hline More than 2 pints/day & 15 & 15 & 30 \\
Nil to 2 pints/day & 594 & 285 & 879 \\
Total & 609 & 300 & 909 \\
Percentage 'heavy' & 2.5 & 5.0 & \\
\hline
\end{tabular}

$\chi^{2}$ test, $p=0 \cdot 044 ;$ relative risk $=2 \cdot 08 ; 95 \%$ confidence limits $=1.005$ to $4 \cdot 32$.

2 Pints $=1136 \mathrm{ml}$.

\section{ALCOHOL}

Subjects were asked about their consumption of beer, wines, and spirits separately. The score for all three was added to give a total alcohol score. Those reporting higher scores for total alcohol, past and present, were overrepresented among cases, indicating a possible risk, but comparison of those consuming 10 or more units of alcohol per day with those consuming less did not reveal a significant difference by the $\chi^{2}$ test (one unit of alcohol is half a pint $(284 \mathrm{ml}$ ) of beer, or one glass of wine, or a single whisky). For individual beverages 'heavy drinkers' (more than 4 units per day) of either spirits or beer were overrepresented among cases. The difference for spirits was not statistically significant, but 'heavy' beer drinkers appeared to double their risk of cataract (Table 9). The cataract group had a greater proportion of subjects reporting a high beer consumption than any of the four control groups. All but one of the 'heavy' beer drinkers were male, and in males alone the risk was similar to the overall risk: relative risk=
Table 10 Contingency table for aspirin as a possible protective agent against cataract

\begin{tabular}{lccr}
\hline & Controls & Cases & Total \\
\hline Aspirin & 44 & 15 & 59 \\
No aspirin & 565 & 285 & 850 \\
Total & 609 & 300 & 909 \\
Percentage positive & $7 \cdot 2$ & $5 \cdot 0$ & \\
\hline
\end{tabular}

$\chi^{2}$ test, $p=0 \cdot 2$, not significant .

Table 11 Paracetamol (acetaminophen) as a protective factor against cataract-contingency table

\begin{tabular}{llcl}
\hline & Controls & Cases & Total \\
\hline Paracetamol & 107 & 26 & 133 \\
No paracetamol & 502 & 274 & 776 \\
Total & 609 & 300 & 909 \\
Percentage positive & 17.6 & 8.7 & \\
\hline
\end{tabular}

$\chi^{2}$ test, $\mathrm{p}<0 \cdot 001 ;$ relative risk $=0 \cdot 45 ; 95 \%$ confidence limits $=0.29$ to $0 \cdot 71$.

Table 12 Aspirin-like analgesics as protective factors against cataract

\begin{tabular}{llcl}
\hline & Controls & Cases & Total \\
\hline Aspirin-like analgesics & 185 & 51 & 236 \\
No aspirin-like analgesics & 424 & 249 & 673 \\
Total & 609 & 300 & 909 \\
Percentage positive & $30 \cdot 4$ & $17 \cdot 0$ & \\
\hline
\end{tabular}

$\chi^{2}$ test, $\mathrm{p} \ll<0.001 ;$ relative risk $=0.47 ; 95 \%$ confidence limits $=0.33$ to $0 \cdot 66$.

$2 \cdot 2(95 \%$ confidence limits 1.02 to $4 \cdot 66), p=0.041$. An association between cataract and high alcohol consumption was reported by Clayton et al.

\section{ASPIRIN-LIKE ANALGESICS: PROTECTIVE} FACTORS?

Risk factors are those factors experienced by a significantly greater proportion of cases than of controls. To our surprise some drugs were reported by a greater proportion of controls than of cataract patients, indicating a possible anticataract effect. These drugs were the aspirin-like analgesics (nonnarcotic analgesics). Aspirin was reported by $7 \cdot 2 \%$ of controls and $5.0 \%$ of cases, but this difference was not statistically significant (Table 10). Paracetamol (acetaminophen) was reported by twice as many controls as cases and emerged as a highly significant protective factor, with a relative risk of 0.45 (Table 11). The $95 \%$ confidence limits for this relative risk are $0 \cdot 29$ to $0 \cdot 71$. Consumption of paracetamol for at least four months is associated with a significant protection against cataract. The proportion of subjects reporting other aspirin-like analgesics was also greater among controls than cases, so we analysed 
Table 13 Protection by aspirin-like analgesics in those not reporting steroids

\begin{tabular}{llcl}
\hline & Controls & Cases & Total \\
\hline Aspirin-like analgesics & 172 & 42 & 214 \\
No aspirin-like analgesics & 399 & 226 & 625 \\
Total & 571 & 268 & 839 \\
Percentage positive & $30 \cdot 1$ & $15 \cdot 7$ & \\
\hline
\end{tabular}

$\chi^{2}$ test, $\mathrm{p} \ll<\cdot 001$; relative risk $=0.43 ; 95 \%$ confidence limits $=0.30$ to $0 \cdot 63$.

the data for these drugs as a whole (Table 12). The relative risk was very similar for the entire group, again indicating that either taking aspirin-like analgesics or something closely associated with taking these analgesics had halved the risk of cataract. The extent of protection was very similar in males and females. ${ }^{4}$ The term 'aspirin-like analgesics' includes aspirin, paracetamol, ibuprofen and similar drugs, naproxen, benorylate, mefenamic acid, and flufenamic acid. The proportions of total controls reporting these drugs were $7 \cdot 2 \%$ aspirin, $17.6 \%$ paracetamol, $7 \cdot 2 \%$ ibuprofen family, $4 \cdot 1 \%$ for the rest.

As the implications of the association between these drugs and protection against cataract are so important, it is necessary to be sure that the association is real. It is useful therefore to compare the different control groups lest the result be due to a single group, perhaps the hospital controls, being major consumers of analgesics. In fact aspirin-like analgesics were reported by $29.9 \%, 32 \cdot 1 \%, 32.3 \%$, and $27.0 \%$ of the hospital controls and three community control groups respectively compared with only $17 \%$ of cataract patients. ${ }^{4}$ The close comparability of the four different control groups, all of them differing widely from the cases, enhances our confidence that the association between aspirin-like analgesics and protection against cataract is real. The low $\mathrm{p}$ value adds further support to that view. Many of the subjects reporting aspirin-like analgesics also reported arthritis $(42 \%$ of cases and $36 \%$ of controls), and some of these had also reported taking steroids, a known risk factor for cataract in our population (Table 1). It seemed useful therefore to exclude those reporting steroids from the analysis. On doing so the apparent protection by aspirin-like analgesics increased slightly (Table 13). The apparent protection by paracetamol increased slightly, remaining highly significant (Table 14). Without the steroid takers ibuprofen emerged as a significant protective factor (Table 15).

\section{Discussion}

It appears from these results that a variety of drugs
Table 14 Protection by paracetamol in those not reporting steroids

\begin{tabular}{llcc}
\hline & Controls & Cases & Total \\
\hline Paracetamol & 100 & 22 & 122 \\
No paracetamol & 471 & 246 & 717 \\
Total & 571 & 268 & 839 \\
Percentage positive & $17 \cdot 5$ & $8 \cdot 2$ & \\
\hline
\end{tabular}

$\chi^{2}$ test, $\mathrm{p}<0.001 ;$ relative risk $=0.42 ; 95 \%$ confidence limits $=0.26$ to $0 \cdot 68$.

Table 15 Protection by ibuprofen in those not reporting steroids

\begin{tabular}{lccc}
\hline & Controls & Cases & Total \\
\hline Ibuprofen & 40 & 8 & 48 \\
No ibuprofen & 531 & 260 & 791 \\
Total & 571 & 268 & 839 \\
Percentage positive & $7 \cdot 0$ & $3 \cdot 1$ & \\
\hline
\end{tabular}

$\chi^{2}$ test, $\mathrm{p}<0.025 ;$ relative risk $=0.41 ; 95 \%$ confidence limits $=0.19$ to $0 \cdot 89$.

affect lens opacification but most surprisingly that some, the aspirin-like analgesics, may exert a protective effect. We did not attempt to validate drug consumption. The usual method by blood and urine tests is not possible, because our interest extended to drugs taken in the past. Validation from hospital notes or general practitioner notes would not be useful, as they are not comparable, and some drugs that were most interesting are over-the-counter drugs. However, most patients seem confident in remembering drugs they have taken regularly for at least four months, and any lack of recall should be the same in all groups. Comparisons we have made between the five groups ${ }^{5}$ indicate that the powers of recollection of the different groups are comparable.

\section{STEROIDS}

Steroids were associated with an $80 \%$ increase in the risk of cataract. There are several ways in which steroids could cause cataract. They can increase glucose levels in plasma and aqueous humour, increase cation permeability, inhibit Na-K-ATPase and glucose 6-phosphate dehydrogenase and RNA synthesis ${ }^{6}$ and can bind to lens proteins. ${ }^{7}$ The steroids previously associated with cataract have a side chain structure that permits reaction with amino groups to form a stable adduct. Spironolactone does not have this side chain, but both spironolactone and prednisolone have a carbonyl function on the A ring where protein binding could occur. Prenisoloneprotein adducts were identified in rat lenses opacified by incubation in prednisolone and in cataracts removed from patients who had received prolonged steroid therapy. ${ }^{8}$ 


\section{DIURETICS}

From our results we conclude that spironolactone, a steroid diuretic, is a risk factor for cataract and that other diuretics have little effect either way, except for the apparent protection by cyclopenthiazide. This contrasts with the conclusion from the Edinburgh study that all diuretics are risk factors for cataract, some worse than others, with the degree of risk related to the elevation of plasma urea.'

CIGARETTES AND ALCOHOL

Both 'heavy smoking' and 'heavy beer drinking' appeared as risk factors in this study (Tables 8 and 9). Cigarette smoking was the only factor where the data were stratified after all the interviews had been completed. No close relationship was observed, and comparison of all smokers with non-smokers did not reveal a risk. Furthermore there is a possibility of confounding between cigarette smoking, beer drinking, and work on a military base, which was reported as a risk factor in the preceding paper, ${ }^{5}$ but analysis for interaction between risk factors by means of GLIM (Royal Statistical Society, Edinburgh) indicated that these three risk factors are independent.

\section{ASPIRIN-LIKE ANALGESICS:PROTECTIVE FACTORS?}

The protective effects of aspirin-like analgesics (nonnarcotic analgesics') have been reported briefly by us, ${ }^{4}$ but here we present the contingency tables for individual members of this family. Earlier studies indicating that aspirin protected against cataract in rheumatoid arthritis and diabetic patients ${ }^{1011}$ were criticised. ${ }^{12}$ Subsequently we showed that aspirin could prevent the cyanate-induced opacification of incubated rat lenses. ${ }^{13}$ The strong association between consumption of aspirin, paracetamol, ibuprofen, and similar drugs and protection against cataract in this study does not establish a causal relationship, but if these drugs are not responsible for the protective effect it means that those subjects taking them are protected in some other way, perhaps by the condition for which they took the drugs. However, the drugs were taken for a variety of reasons-about $40 \%$ for arthritis. It seems unlikely that arthritis protects against cataract, and it would have to be an extremely powerful effect fully to explain the results, because only $36 \%$ of the controls reporting these drugs had also reported arthritis. It is no more likely that suffering pain protects against cataract. We can think of no explanation other than a direct protection against cataract by aspirin-like analgesics. Most of the standard criteria for a causal relationship ${ }^{14}$ are satisfied in this study. The only previous link between the aspirin-like analgesics and cataract was in the studies of aspirin. Before our study there was no suggestion that paracetamol, ibuprofen, and the other drugs might have any protective effect.

Various mechanisms have been proposed for the apparent protective effect of aspirin, but most recently we have favoured the view that acetylation of the lens proteins served to protect them against chemical insults such as cyanate, glucose, glucose 6phosphate, and prednisolone that are associated with cataract. ${ }^{13}$ This mechanism received further support from laboratory studies of Rao et al. ${ }^{15}$ This explanation cannot be extended to the other aspirin-like analgesics, because most of them lack an acetyl group and therefore cannot acetylate proteins. A mechanism involving prostaglandins is superficially attractive, but paracetamol, which is a feeble inhibitor of prostaglandin synthesis, appears strongly protective against cataract, whereas indomethacin, a powerful inhibitor of prostaglandin synthesis, is not protective, being reported by $3 \cdot 1 \%$ of controls and $3.3 \%$ of cases. They may act by lowering blood glucose levels. ${ }^{4}$ Aspirin-like analgesics lower fasting blood glucose levels in diabetics and non-diabetics ${ }^{1617}$ and improve glucose tolerance 161819 and the insulin response to glucose. ${ }^{17} 19$ These properties are shared by aspirin, salicylates, and ibuprofen but not by indomethacin. ${ }^{2022}$

If aspirin-like analgesics are protective because they lower blood glucose, it would imply that the level in many subjects aged 50 to 79 is higher than is healthy for the lens. There is some evidence to support that notion. First, diabetes is such a powerful risk factor ${ }^{3}$ that any elevation of blood glucose could be harmful. Indeed, it was shown in the Edinburgh survey that the mean glucose level in cataract patients exceeded that of controls even when diabetics were excluded from the analysis. ${ }^{23}$ Secondly, it has been reported that $44 \%$ of cataract patients have an abnormal glucose tolerance curve.$^{24} \mathrm{~A}$ moderate but chronic elevation of glucose concentration is unlikely to have any osmotic effect and is more likely to act through non-enzymic glycosylation of lens proteins. This reaction occurs to most proteins, notably to long-lived proteins found in the tissues that are damaged in diabetes. ${ }^{25}$ If the aspirin-like analgesics protect against cataract by lowering blood glucose levels, it is possible that they give some protection against other glucose-induced damage-perhaps retinopathy, neuropathy, and basement membrane damage. An apparent protection by aspirin against diabetic retinopathy has been noted. ${ }^{2627}$

A second case control study in Oxford that incorporates more detailed questions on analgesics has been started so that the dosage required of a protective effect can be elucidated. There are studies indicating that low-dose aspirin protects against 
myocardial infarction, unstable angina, and strokes. Additional protection against cataract would be a great bonus, although some might prefer paracetamol as a potential anticataract drug. Indeed, it is possible that paracetamol is also effective against the above life-threatening conditions.

We are grateful to Professor $\mathrm{N}$ Wald for advice and for help in planning the questionnaire. We thank Mr A J Bron, Drs R A E Spilling, J Ross, D Minassian, L O'Brian, and G Edwards for helpful discussions.

We are grateful to the consultants of the Oxford Eye Hospital, Ear, Nose and Throat Department, and the Slade Hospital, and to local general practitioners for access to their patients. We thank the TFC Frost Charitable Trust for a grant for expenses.

\section{References}

1 Clayton RM, Cuthbert J, Duffy J, et al. Some risk factors associated with cataract in SE Scotland: a pilot study. Trans Ophthalmol Soc UK 1982; 102: 331-6.

2 Minassian D, Mehra VJ, Jones BR. Dehydrational crises from severe diarrhoea or heatstroke and risk of cataract. Lancet 1981; i: $751-3$.

3 van Heyningen $\mathrm{R}$, Harding JJ. Risk factors for cataract: diabetes, myopia and sex. In: Courtois Y, Forette B, Knook D, eds. Modern trends in ageing research. Paris: INSERM/Libbey. In press.

4 van Heyningen $\mathbf{R}$, Harding JJ. Do aspirin-like analgesics protect against cataract? A case-control study. Lancet 1986; i: 1111-3.

5 van Heyningen $\mathrm{R}$, Harding $\mathrm{JJ}$. A case-control study of cataract in Oxfordshire: some risk factors. Br J Ophthalmol 1988; 72: 804-8.

6 Harding JJ, Crabbe MJC. The lens: development, proteins, metabolism and cataract. In: Davson $\mathrm{H}$, ed. The eye. 3rd ed. London: Academic Press, 1984; 1B: 207-492.

7 Bucala R, Fishman J, Cerami A. Formation of covalent adducts between cortisol and $16 \alpha$-hydroxyestrone and protein: possible role in the pathogenesis of cortisol toxicity and systemic lupus erythematosus. Proc Natl Acad Sci USA. 1982; 79: 3320-4.

8 Manabe S, Bucala R, Cerami $A$. Non-enzymatic addition of glucocorticoids to lens proteins in steroid-induced cataracts. J Clin Invest 1984; 74: 1803-10.

9 Joint Formulary Committee. British National Formulary. London: British Medical Association and Pharmaceutical Society of Great Britain, 1986; 12: 163.

10 Cotlier E. Aspirin and senile cataract in rheumatoid arthritis. Lancet 1981 ; i: 338-9.
11 Cotlier E, Sharma YG, Niven T, Brescia M. Distribution of salicylate in lens and intraocular fluids and its effect on cataract formation. Am J Med 1983; 74: 83-90.

12 Seigel D, Sperduto RD, Ferris F. Is ASA therapy for cataract justified? Can J Ophthalmol 1982; 1: 135-6.

13 Crompton M, Rixon KC, Harding JJ. Aspirin prevents carbamylation of soluble lens proteins and prevents cyanate-induced phase separation opacities in vitro: a possible mechanism by which aspirin could prevent cararact. Exp Eye Res 1985: 40: $297-$ 311.

14 Vessey MP. Case-control studies in the evaluation of drug safety. Sécurité medic 1982; 111-21.

15 Rao GN, Lardis MP, Cotlier E. Acetylation of lens crystallins: a possible mechanism by which aspirin could prevent cataract formation. Biochem Biophys Res Commun 1985; 128: 1125-32.

16 Reid J, Macdougall AI, Andrews MM. Aspirin and diabetes mellitus. Br Med J 1957; ii: 1071-4.

17 Giugliano D, Torella R, Siniscalchi N, Improta L, D Onofrio F. Effect of acetylsalicylic acid on insulin response to glucose and arginine in normal man. Diabetologia. 1978; 14: 359-62.

18 Hecht A, Goldner MG. Reappraisal of hypoglycemic action of acetylsalicylate. Metabolism 1959; 8: 418-28.

19 Micossi P, Pontiroli AE, Baron SH, et al. Aspirin stimulates insulin and glucagon secretion and increases glucose tolerance in normal human and diabetics. Diabetes 1978; 27: 1196-204.

20 Widström A. Influence of indomethacin on glucose-induced insulin response in normal man: Role of prostaglandins in the rapid insulin release? Hormone Metab Res 1977; 9: 172-5.

21 Chen M, Robertson RP. Effects of prostaglandin synthesis inhibitors on human insulin secretion and carbohydrate tolerance. Prostaglandins 1979; 18: 557-67.

22 Rosen P, Hohl C. Prostaglandins and diabetes. Ann Clin Res 1984; 16: 300-13.

23 Clayton RM, Cuthbert J, Phillips CI, et al. Analysis of individual cataract patients and their lenses: a progress report. Exp Eye Res 1980; 31: 553-66.

24 Dugmore WN, Tun K. Glucose tolerance tests in 200 patients with senile cataract. Br J Ophthalmol 1980; 64: 689-92.

25 Harding JJ. Non-enzymic covalent post-translational modification of proteins in vivo. Adv Protein Chem 1985; 37: 247-334.

26 Powell EDU, Field RA. Diabetic retinopathy and rheumatoid arthritis. Lancet 1964; ii: 17-8.

27 Carroll WW, Geeraets WJ. Diabetic retinopathy and salicylates. Ann Ophthalmol 1972; 4: 1019-46.

Accepted for publication 3 September 1987. 